\title{
FROM DISASTER TO UNDERSTANDING
}

\author{
FORMATION AND ACCOMPLISHMENTS \\ OF THE GULF OF MEXICO RESEARCH INITIATIVE
}

By Leigh A. Zimmermann, Michael G. Feldman, Debra S. Benoit, Michael J. Carron, Nilde Maggie Dannreuther,

Katie H. Fillingham, James C. Gibeaut, Jennifer L. Petitt, Jarryl B. Ritchie, Rosalie R. Rossi, Stephen H. Sempier, J. Kevin Shaw,

Jessie L. Swanseen, Charles A. Wilson, Callan J. Yanoff, and Rita R. Colwell

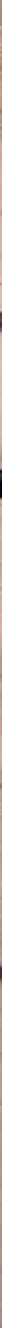




\section{We are fighting an omnidirectional, almost indeterminate threat...}

\section{We are trying to protect the entire Gulf Coast at the same time.}

ABSTRACT. The Gulf of Mexico Research Initiative (GoMRI) was created in 2010 following the catastrophic Deepwater Horizon explosion and oil spill. BP engaged Rita Colwell to form and lead an independent board of experts to oversee an unprecedented program of scientific research on the effects of the spill. As a new and uniquely funded organization, GoMRI quickly developed and implemented a set of management processes, policies, and frameworks while simultaneously building an interconnected research community that eventually grew to nearly 4,500 individuals. The GoMRI Research Board and Management Team successfully produced and operated a system for requests for proposals, grants management, scientific and programmatic data management, and outreach and education, and assembled a scientific synthesis of results to create a lasting legacy 10 years after the disaster. Here, we document the challenges and key decisions underlying the design and operation of GoMRI as a model for independent, industry-funded research. In short, GoMRI represents a unique multi-sector partnership and a community of researchers that will advance science in the Gulf of Mexico and elsewhere for decades to come.

\section{INTRODUCTION}

On April 20, 2010, the TransOcean Deepwater Horizon (DWH) drilling rig lost control of a well, resulting in a catastrophic explosion approximately $66 \mathrm{~km}$ (41 miles) off the Louisiana coast. The TransOcean drilling rig operated on the BP-owned Macondo lease in the Mississippi Canyon, where the water was $\sim 1,500 \mathrm{~m}(\sim 5,000 \mathrm{ft})$ deep. Operations were in progress to temporarily abandon the well, a process involving filling a portion of the well hole with a cement plug. The plug failed, releasing gas and causing a major explosion and fire. Tragically, 11 individuals lost their lives and 17 were injured. Two days later, on April 22, 2010, the rig sank, and oil began to flow from the broken wellhead into the surrounding water (NCBPDHOSOD, 2011).

It was not until 87 days later that the well could be capped. By then, millions of barrels of oil and gas had been released into the Gulf of Mexico. This was when the Gulf of Mexico Research Initiative (GoMRI) story began. and diverse ecology, compared to areas without seeps (Weiman et al., 2021, in this issue).

Over the past 200 years, expanding human communities and activities in the Gulf of Mexico region have negatively influenced its rich and productive ecosystem. McKinney et al. (2021, in this issue) describe how the Gulf has become a thoroughfare for commerce and an international center for hydrocarbon mining, storage, and processing, as well as a collection basin for outflows from countries surrounding the Gulf. It has been subjected to many sources of anthropogenic pollution, including hydrocarbons discharged from ships, terrestrial runoff, and oil well failures (McKinney et al., 2021, in this issue; Transportation Research Board and National Research Council, 2003).

Anthropogenic influences on the ecosystem, notably from the exploitation of oil and gas, have on occasion been extreme, with several notable largescale oil-related releases into the Gulf (Farrington et al., 2021, and Wiesenburg et al., 2021, both in this issue). For example, the 1978 Ixtoc 1 spill that occurred offshore from the Bay of Campeche, Mexico, leaked 3.4 million barrels (142.8 million gallons) of crude oil over a nine-month period, some of which eventually reached the Texas coast. Major storms, such as Hurricane Katrina, have caused damage to oil and gas infrastructure, resulting in episodic release of oil
Approximate Conversions of Crude Oil by Volume

1 barrel $=42$ gallons $=0.1364$ metric tonnes $=0.159$ kiloliters 
into vulnerable wetlands, including those along coastal Louisiana and Texas (Pine, 2006). Scientific studies of the nature and impacts of these releases were carried out after each major incident but generally were not extensive until the DWH blowout (McKinney et al., 2021, in this issue). Investigations by the Natural Resource Damage Assessment ${ }^{1}$ and associated legal processes concluded BP was responsible for the discharge of 3.19 million barrels (134 million gallons) of oil into the Gulf of Mexico, although the scientific consensus was that the overall input was closer to 5 million barrels (210 million gallons), indicating this to be the most significant accidental oil spill in history (DHNRDAT, 2016).

\section{Formation of the Gulf of Mexico \\ Research Initiative}

Immediately following the blowout on April 22, 2010, several federal agencies and the companies involved joined forces to attempt to cap the well under the National Oil and Hazardous Substances Pollution Contingency Plan2 (NCBPDHOSOD, 2011). Within weeks, early discussions were being held regarding establishment of a scientific study of the DWH region; this study would become GoMRI. The framework for a 10-year, $\$ 500$ million, independent research program to study the impacts and effects of the oil spill was developed voluntarily by BP and initiated with a single phone call from BP Chief Scientist Ellen Williams to Rita Colwell, former director of the US National Science Foundation. A central premise of the program was that neither BP nor the Gulf state governors would influence selection of the research to be funded or the resulting publications. With input from the Gulf of Mexico Alliance (https://gulfofmexicoalliance.org/),
Colwell assembled a team of international, US, and Gulf of Mexico-based research scientists and university administrators to direct research associated with the massive spill of oil into the Gulf. GoMRI was formally announced on May 24, 2010, a month after the DWH catastrophe.

Together, the GoMRI Research Board (RB), BP, and the Gulf of Mexico Alliance drafted a Master Research Agreement that provided a formal framework for the program (https://gulfresearchinitiative. org/about-gomri/master-researchagreement/). A management team was established to support $\mathrm{RB}$ operations and assist in developing and managing the program. The Master Research Agreement was signed on December 1, 2011, and thereafter provided a blueprint for GoMRI operations, with only small adjustments in subsequent amendments as the program evolved. Tasks undertaken by the GoMRI team included:

- Developing and implementing a request for proposal (RFP) process

- Selecting proposals for funding

- Negotiating and entering into research award agreements, establishing fiscal diligence of expenditure of funds, and managing associated reporting

- Designing and implementing a database to contain the scientific data produced by funded projects, along with programmatic data (funded projects, personnel, and publications)

- Designing and maintaining a website for GoMRI that would be publicly accessible

- Designing and facilitating a program for engagement with key stakeholders via an Outreach and Communications Plan

- Facilitating a scientific synthesis of the research undertaken
GoMRI Research Board and

\section{Management Team}

Working within the structure created by the Master Research Agreement, the RB established bylaws, a code of conduct, and policies and processes necessary for guiding operations, setting scientific direction, and ensuring program integrity. The RB established a conflict-of-interest policy for all RB members, GoMRI Management Team (GMT) staff, and GoMRI-funded Principal Investigators (PIs) and co-PIs. Colwell chaired the RB, which convened annually as a full board, more frequently as needed. $\mathrm{RB}$ members led and served on various committees to provide detailed guidance to the programmatic operations, for example, RFP development, education and communications, data management, and legacy/synthesis.

The RB created a Chief Scientific Officer position to coordinate research activities, liaise with researchers on scientific issues, and facilitate communication across the entire GoMRI program. The Chief Scientific Officer was hired in 2012 and served as a member of the GMT, reporting to the $\mathrm{RB}$ Chair and bridging the GoMRI Management Team, the Research Board, the research community, the Gulf of Mexico Alliance, and BP. The Chief Scientific Officer and the Executive Director of the program attended all meetings of the RB ex officio to provide program updates and other information.

The Master Research Agreement assigned leadership, scientific direction, and programmatic oversight to the $\mathrm{RB}$ and administrative tasks to the Gulf of Mexico Alliance. The Gulf of Mexico Alliance contracted with the Consortium for Ocean Leadership and the Northern Gulf Institute at Mississippi State University for assistance with project management, RFP development and execution, and outreach

\footnotetext{
${ }^{1}$ Natural Resource Damage Assessment (NRDA) is the legal process that federal agencies like NOAA-together with states and Indian tribes-use to evaluate the impacts of oil spills, hazardous waste sites, and ship groundings on public natural resources along the nation's coasts and throughout its interior.

2 The National Oil and Hazardous Substances Pollution Contingency Plan, more commonly called the National Contingency Plan or NCP, is the federal government's blueprint for responding to both oil spills and hazardous substance releases. The first NCP was developed and published in 1968 in response to a massive oil spill from the oil tanker Torrey Canyon off the coast of England (https://www.epa.gov/emergency-response/ national-oil-and-hazardous-substances-pollution-contingency-plan-ncp-overview).
} 
activities. The Harte Research Institute for Gulf of Mexico Studies at Texas A\&M University-Corpus Christi was selected to serve as data administrator. The American Institute of Biological Sciences was chosen to serve as the RB support entity. Thus, the combination of these groups and responsibilities served as the GMT (Figure 1).

\section{Enabling the Best Research}

In June 2010, while GoMRI was in its early stage of development, BP distributed $\$ 45$ million of the designated $\$ 500$ million for rapid response research and sample collection to academic institutes in Florida, Alabama, Mississippi, and Louisiana, and to the National Institutes of Health. These short-term grants were to enable early sample collection for research on the oil spill until GoMRI was fully organized to begin operations. This distribution was made before the Master
Research Agreement was finalized and prior to identification of GoMRI research themes (described below).

Following this initial investment, the $\mathrm{RB}$ developed and released the first RFP, or RFP-I, with a goal of building on, and extending, existing scientific research capacity, activity, and collaboration in the Gulf of Mexico region. RFP-I supported teams of scientists, in the form of research consortia, which the RB defined as four or more collaborating institutions led by a single Gulf institution. In addition to research consortia, the $\mathrm{RB}$ also chose to support smaller groups of researchers and individual investigators. The RB prepared a second request for proposals (RFP-II) designed to direct funding to individuals and small groups who proposed research that would address the GoMRI research themes (described below) and complement consortia research. Meanwhile, a fast-track, third call for proposals (RFP-III) was implemented to ensure high-priority data collection begun in the previous year would continue during the next field season, namely the summer of 2011. While the larger RFP-I and RFP-II were being prepared for release, RFP-III was the first major RFP funding awarded by the program (Figure 2 ).

During the 10 years the program was in operation, the GoMRI RB released six RFPs, cumulatively awarding more than $\$ 410$ million for scientific research when combined with the initial investment by BP (Tables 1 and 2). Each RFP was unique; RFP-I and RFP-IV funded research consortia, RFP-III funded data collection, RFP-II and RFP-V funded individual investigators and small research teams, and the final call for proposals, RFP-VI, funded both consortia and small investigator teams.

\section{GULF OF MEXICO RESEARCH INITIATIVE STRUCTURE}

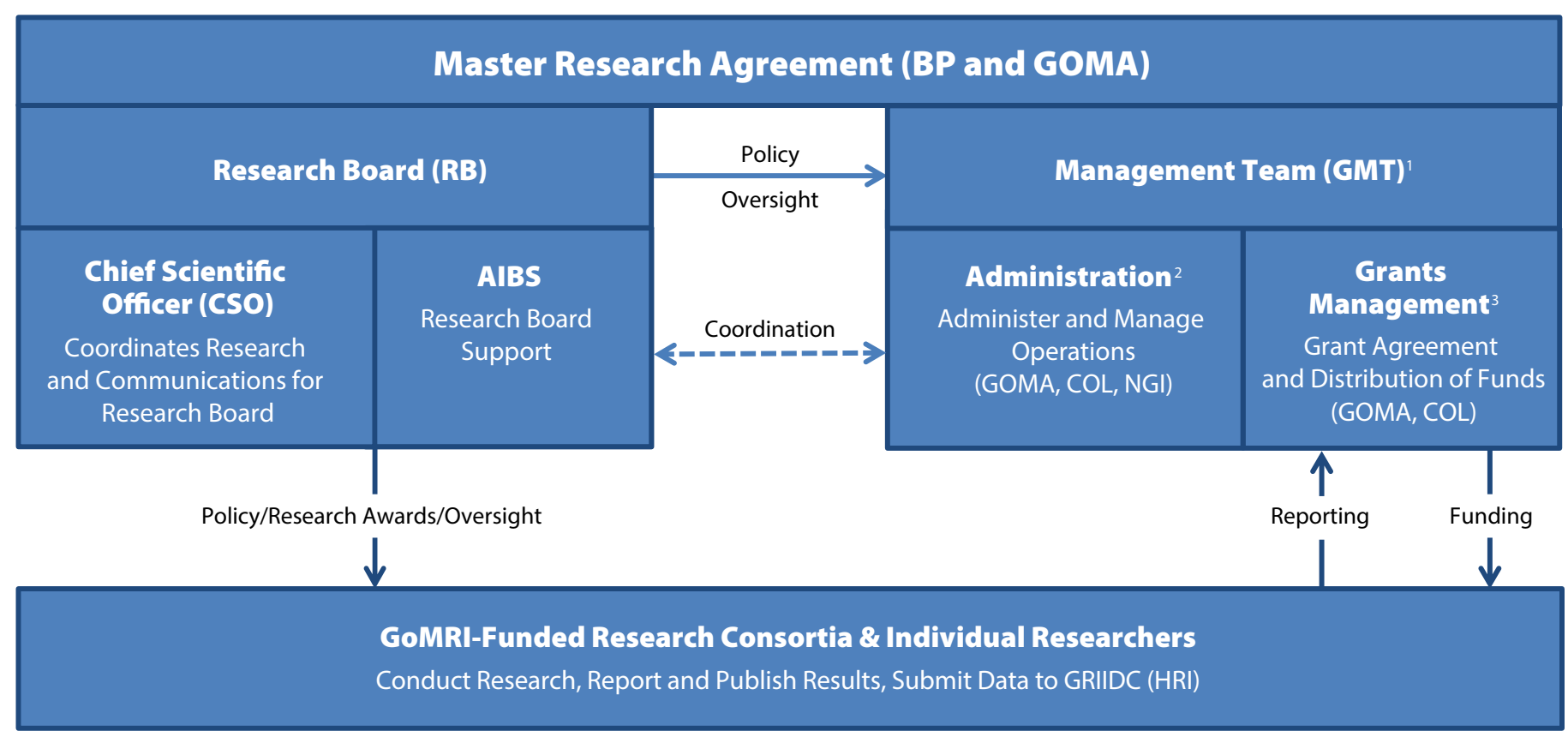

AIBS - American Institute of Biological Sciences

COL - Consortium for Ocean Leadership

GOMA - Gulf of Mexico Alliance

GRIIDC - Gulf of Mexico Research Initiative Information and Data Cooperative

HRI - Harte Research Institute

NGI - Northern Gulf Institute
Notes: COL, NGI, HRI under contract to GOMA

${ }^{1} \mathrm{CSO}$ and AIBS member of GMT

${ }^{2}$ Administrative Unit in Master Research Agreement

${ }^{3}$ Grants Unit in Master Research Agreement 


\section{Identification of Research Themes}

Concurrent with the establishment of GoMRI, the research community was convened to inform a scientific response to the ongoing spill, and more than 200 scientists assembled on June 3, 2010, at Louisiana State University to discuss the urgent need to respond (Consortium for Ocean Leadership, 2010). Key topics of the meeting covered in breakout ses- sions included estimating the flow rate of oil at the wellhead, projecting the fate of the oil, and determining potential effects of the oil and dispersants on the environment and human health. Participants identified science challenges associated with the spill: determining its magnitude, tracking the fate and transport of oil, and evaluating ecological and human impacts. The experts also identified several cross- cutting challenges: the need for central coordination in deploying scientific assets, the necessity of avoiding duplication of effort, the importance of central management and standardization of data and metadata formats, and the urgency of launching baseline studies.

Subsequent workshops further refined the list of research and development topics, including dispersant

MAY JUNE JULY 201020102011
20122013

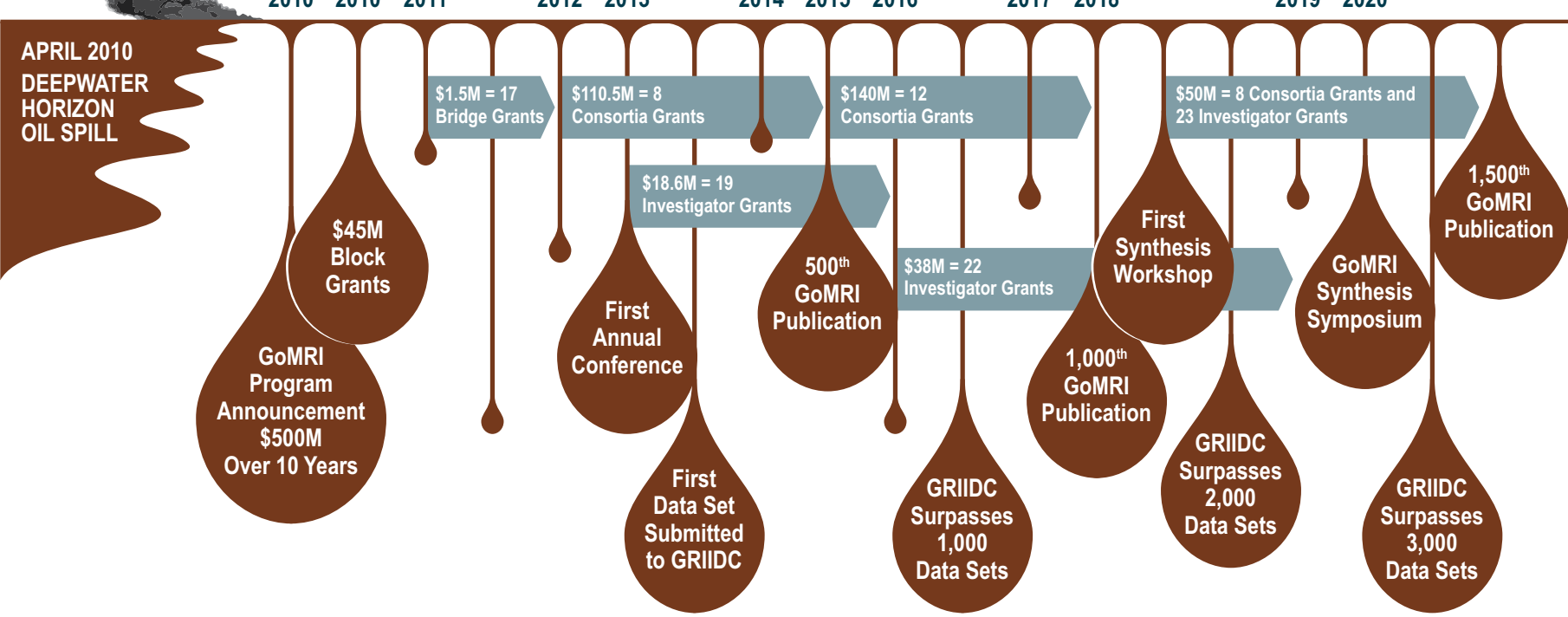

20192020
TABLE 1. Summary of GoMRI funding by investment area. The program was designed to maximize funding awarded to the research community while minimizing administrative and operating costs to approximately $10 \%$ of overall funding. Data management, to ensure all data were archived and available for future use, included software development and implementation, storage, and support of GRIIDC through 2030. Outreach and communications included support for external partners but not for activities of the research consortia and their projects, whose costs are captured under research. A multi-year effort to summarize and synthesize research findings is included under research investment.

\section{INVESTMENT AREA}

\$ MILLION \% OF TOTAL

\begin{tabular}{lcc} 
Research & $\$ 413.1$ & $82.6 \%$ \\
\hline Data Archiving & $\$ 20.6$ & $4.1 \%$ \\
\hline Outreach \& Communication & $\$ 15.5$ & $3.1 \%$ \\
\hline Administration \& Operations & $\$ 50.8$ & $10.2 \%$ \\
\hline TOTAL & $\mathbf{\$ 5 0 0 . 0}$ & $\mathbf{1 0 0 . 0 \%}$ \\
\hline
\end{tabular}

TABLE 2. Detailed information concerning the six GoMRI RFPs.

\begin{tabular}{llccc} 
RFP & $\begin{array}{l}\text { TYPE OF } \\
\text { SOLICITATION }\end{array}$ & $\begin{array}{c}\text { PROPOSALS } \\
\text { RECEIVED }\end{array}$ & AWARDS & $\begin{array}{c}\text { FUNDING } \\
\text { (\$ MILLION) }\end{array}$ \\
\hline RFP - III & Bridge & 111 & 17 & $\$ 1.5$ \\
\hline RFP - I & Consortia & 78 & 8 & $\$ 110.5$ \\
\hline RFP - II & Investigator & 410 & 19 & $\$ 18.6$ \\
\hline RFP - IV & Consortia & 47 & 12 & $\$ 148.4$ \\
\hline RFP - V & Investigator & 288 & 22 & $\$ 38.0$ \\
\hline RFP - VI & Consortia \& Investigator & 186 & 31 & $\$ 50.0$ \\
\hline TOTALS & & $\mathbf{1 , 1 2 0}$ & $\mathbf{1 0 9}$ & $\mathbf{\$ 3 6 7 . 0}$ \\
\hline
\end{tabular}


efficacy and effects, spill trajectory modeling, and detection of surface and subsurface oil. The list also included analysis of the human dimension related to spill response, seafood safety, information management, and dialogue among researchers and responders to ensure transfer of research results to effective practices (Institute of Medicine, 2010; Coastal Response Research Center, 2011; Sumaya et al., 2013).

The GoMRI RB incorporated the recommendations from these meetings and the collective expertise of the research scientists to establish five themes to guide GoMRI research:

- PHYSICAL DISTRIBUTION, dispersion, and dilution of petroleum (oil and gas), its constituents, and associated contaminants (e.g., dispersants) under the action of physical oceanographic processes, air-sea interactions, and tropical storms

- chemical eVolution and BioLOGICAL DEGRADATION of the petroleum/dispersant system and subsequent interactions with coastal, openocean, and deepwater ecosystems

- ENVIRONMENTAL EFFECTS of the petroleum/dispersant system on the seafloor, water column, coastal waters, beach sediments, wetlands, marshes, and organisms, and the science of ecosystem recovery

- TECHNOLOGY DEVELOPMENTS for improved response, mitigation, detection, characterization, and remediation associated with oil spills and gas releases

- PUBLIC HEALTH IMPACTS of oil spills, including behavioral, socioeconomic, environmental risk assessment, community capacity, and other population health considerations and issues

\section{Request for Proposal Development and Execution}

The fundamental goal of the RB was to fund the best science using a solicitation and review process of the highest integrity. An evaluation process was adapted from the US National Science Foundation
(NSF) merit review system, including administrative review of each proposal for required elements and compliance. Rigorous peer review was conducted by outside experts who provided recommendations, based on predefined scoring and weighting, to the RFP committee and the RB. The GMT, with instructions from the RB, identified reviewers representing expertise across all five GoMRI research themes. Peer reviewers were required to sign conflict-of-interest and nondisclosure agreements prior to receiving review materials. Final selection of awardees was made by the RB from the most highly ranked proposals.

RFPs were developed by committees of the RB, with logistical support provided by the Chief Scientific Officer and the GMT staff. To be considered, proposals were required to address one or more of the five GoMRI research themes, with emphasis on interdisciplinary science encouraged. The six RFPs varied slightly, based on specific goals and requirements of each RFP. Letters of intent, preliminary proposals, full proposals, or a combination of these elements were used in the RFP selection process. The elements and submission compliance expectations were developed for each RFP solicitation and were clearly defined.

\section{Grants Administration}

Because it was a novel and uniquely funded organization, GoMRI, out of necessity, had to develop and implement a set of management processes, policies, and frameworks to ensure each research grant was efficiently and effectively administered and monitored. This process drew on best management practices of established funding organizations, such as NSF, to meet specific goals and objectives of GoMRI. At the end of the 10-year program, the GoMRI grant administration team had successfully executed and managed more than 100 research grants, varying in size from $\sim \$ 41,000$ to $\sim 21$ million, awarded under six RFPs. Primary goals of the grant administration process were to:
- Ensure the GMT and RB monitored progress of every research grant, including spending and impactful changes to the proposed scope of work - Maintain consistency of management across all awards throughout the lifetime of the GoMRI program

- Minimize management burden on PIs, allowing them to focus their efforts on science

- Enhance the GoMRI mission by encouraging collaboration and communication among research teams and ensuring PIs were kept informed of overall GoMRI activities.

Each grant was managed by an administrator throughout the pre- and postaward processes, in effect managing each award from contract negotiation to closeout. This proved to be an effective strategy that provided each PI a single point of contact for administrative questions and distributed the grant administration workload equitably. It proved especially useful at the height of GoMRI grant activities when RFPs I and II were winding down and RFPs IV, V, and VI were either in full operation or just beginning. GoMRI grant administration practices were essentially stable for the lifetime of the program, with only a few changes needed. Best practices and lessons learned from the GoMRI experience in grant execution and monitoring during the 10 years the program was in operation are highlighted below.

\section{Grant Execution}

Upon selection of awards, the GMT engaged each lead institution in negotiations guided by the Master Research Agreement, utilizing a contract framework modeled after that of NSF, a process familiar to management and investigators of all institutions. Contracts were standard for GoMRI research grants and, although negotiation on language was permitted, the overwhelming majority of the contracts were consistent with the GoMRI process. This allowed smooth execution of the contracts, with the process 
becoming more streamlined with each new RFP, as institutions became increasingly familiar with the GoMRI contract.

An important charge to the grant administration team was compliance monitoring of project expenditures and progress. Whereas NSF tracks semiannual or annual progress, the GoMRI $\mathrm{RB}$ opted to require quarterly financial and research progress reports and an annual summary of activities. These reports provided an invaluable source of information, notably for the GMT in anticipating potential problems, keeping the RB informed, identifying website content, and promoting cross-project connections. To minimize the administrative burden for the PIs, standardized templates were created for the reports and were pre-populated with relevant information for each project. Quarterly financial reports allowed comparison of actual expenditures with the approved budget to determine expenditures (i.e., the "burn rate") for each project. Activity reports were submitted in two parts. An activity spreadsheet allowed tracking of publications, presentations, field and outreach activities, and GoMRI participants. These data were incorporated into a Research Information System that we discuss below. In addition, the activity report narrative provided information on plans for the next quarter and an opportunity for the PI to highlight problems and/or obstacles.

While quarterly and annual reports kept the RB and GMT apprised of ongoing activities, GoMRI was designed to be collaborative. Communication across the research community was facilitated by quarterly conference calls that included all PIs, the GMT, and the RB. These calls provided research and administrative updates and encouraged cooperation and sharing of best practices. This proved critical for the RB and GMT in tracking research progress, and, more importantly, in building community and promoting collaboration.

An important monitoring tool implemented by the GMT was the site visit, which included administrative and RB participation. For each award, the grant administrator organized a site visit to review and discuss institution policies for pre- and post-award management. Serious concerns or findings of note proved to be rare, but the site visit was an opportunity for researchers and administrators to forge working relationships and gain context on the science behind each project, enhancing effective and less intrusive grant management. $\mathrm{RB}$ site visits were conducted for consortia that received awards under RFP-I and RFP-IV. The purpose of these site visits was to establish direct interaction between researchers and the $\mathrm{RB}$ and to provide the $\mathrm{RB}$ with detailed updates on research progress and opportunities to discuss findings and new directions with PIs and co-PIs. The site visits also provided context to the $\mathrm{RB}$ for requests for significant changes that required $\mathrm{RB}$ approval, thus facilitating an efficient and informed approval process.

The final phase of grant monitoring was closeout for each award. Prior to award end date, grantees were provided a checklist (reports, publications, proof of data set(s) submitted to the archives, equipment lists, patents/inventions, final financial statements, certification of costs, and return of unspent funds) required to be completed before the award could be recorded as compliant and officially closed. Mandatory data submittal proved to be a management challenge, particularly for an efficient and timely closeout of an award, but ultimately worth the benefit gained by leaving a working legacy of GoMRI results and findings in the data submissions.

\section{DATA STORAGE AND ACCESSIBILITY}

The Master Research Agreement explicitly stated that the program would create and manage a research database to maintain full records of all funded projects, personnel, and publications and ensure resulting scientific data were fully accessible. To meet these two objectives, GoMRI created one system for housing scientific data and a second system for administrative tracking and information collection.

\section{Gulf of Mexico Research Initiative} Information and Data Cooperative

The Gulf of Mexico Research Initiative Information and Data Cooperative (GRIIDC) was established at the Harte Research Institute for Gulf of Mexico Studies at Texas A\&M University-Corpus Christi to serve as the data repository for all GoMRI research. Although previous oil spills involved significant research, not all data resulting from those events are publicly available (Reichman et al., 2011). Field data collected at a specific time and place are valuable to preserve (McNutt et al., 2016) and extremely useful in providing a baseline, especially for record keeping of research on environmental disasters. There are many benefits in sharing data, because data from previous oil spills can be reanalyzed and verified, preventing duplication of effort and maximizing resources (Tenopir et al., 2011), as well as providing for transparency and reproducibility (Campbell et al., 2018). For these reasons, GoMRI moved to establish GRIIDC as the data repository for the program.

Initially, GRIIDC faced the unique challenge of developing a data management system at the same time researchers were collecting immediate post-spill data. GoMRI researchers were required to submit all data within one year of data collection/generation or at the time of publication, which was not common practice at the time GoMRI was launched. Many researchers had never been required to submit data to a repository and were not aware of best practices for organizing data or collecting the metadata linked to each data set. GRIIDC quickly recognized the need for cooperation by the research community and established an advisory committee to address these challenges. The GRIIDC advisory committee included representatives from the following: each GoMRI research consortium, the GoMRI RB, the National Oceanic and 
Atmospheric Administration (NOAA) National Centers for Environmental Information (NCEI), the GMT, and GRIIDC. Leadership and guidance provided by the GRIIDC advisory committee proved instrumental in developing best practices.

To encourage data sharing, GRIIDC offered incentives, including citable data packages, digital object identifiers (DOIs), data curation that ensured data were documented, and support in the compliance process. Training and communication provided to the research community were key to successful data submission and implementation of data sharing policies. GRIIDC provided training on data management, submission, and curation, as well as information about the benefits of data sharing. GRIIDC published guidance documents, organized workshops, and held training webinars on best practices for a range of data topics: categorizing, compression, organization, and submission.

Entering properly documented and complete sets of data into the GRIIDC repository was the first step in effective data sharing. GRIIDC employed several strategies to ensure the research database was discoverable, accessible, and useful, not just for scientists but also for the public. GRIIDC joined the Data Observation Network for Earth (DataONE) (https://search.dataone.org/data) as a node and deployed an Environmental Research Division Data Access Program (ERDDAP) server (https://erddap.griidc. org/erddap) to provide user selected subsets of oceanographic data. DOIs assigned to the data sets are accessible through the search application on the GRIIDC website (https://data.gulfresearchinitiative.org/ search). GoMRI required all publications to acknowledge GoMRI funding and provide the data set DOI, thus linking GRIIDC data sets to an associated publication.

Innovations and newly developed best practices helped position GoMRI and GRIIDC at the forefront of the data sharing movement (Gibeaut, 2016). Open data, no longer a foreign concept, is now a commonplace activity for researchers, with journals and funding agencies increasingly requiring data to be publicly available. In addition to GoMRI data, GRIIDC houses data generated by the Florida RESTORE Act Centers of Excellence Program; the Mississippi Based Center of Excellence; the Texas OneGulf Center of Excellence; the National Academies of Sciences, Engineering, and Medicine's Gulf Research Program; and the Harte Research Institute for Gulf of Mexico Studies. GRIIDC, with more than 3,000 data sets, 83 terabytes of data, 394 research groups, and 2,850 researchers (as of the date of this publication), ensures a GoMRI data and information legacy as the premier data repository, portal, and resource for the Gulf region.

\section{Research Information System}

The Research Information System (RIS) was created and is managed by the Northern Gulf Institute at Mississippi State University as a relational database framework for tracking and collecting information for GoMRI. It was designed to serve as a resource for program management, information dissemination, and administrative oversight. The RIS and associated tools allowed GoMRI to inventory programmatic data from all funded projects carried out by more than 4,500 researchers working at hundreds of institutions in 43 states and 17 countries. RIS allowed GoMRI staff to track metrics of research productivity, including nearly 5,500 conference presentations and more than 1,500 peer-reviewed publications. Additionally, publications were monitored by the RIS, helping to ensure that all GoMRI attribution and data sharing requirements were met.

RIS is publicly accessible on the GoMRI website (https://research. gulfresearchinitiative.org). The site is continuously updated and provides a structured presentation of GoMRI-funded projects. Each project has an information page cataloguing publications, presentations, and personnel. A complete bibli- ography of GoMRI-funded manuscripts, books, and book chapters is included. Multiple search tools are integrated into the website, providing access to personnel, subject matter, keywords, and thematic search. This site provides program and project background information that integrates the RIS with content throughout the GoMRI main site.

\section{SHARING CRITICAL AND TIMELY INFORMATION}

From its initiation, GoMRI, the RB, and BP placed high importance on disseminating research results and discoveries to a wide variety of audiences. The program achieved this objective using a threepronged approach: outreach activities led by the GoMRI-funded researchers along with outreach professionals; GMT activities at the program level; and partnerships with the Smithsonian Ocean Portal, Screenscope Inc., and four regional Sea Grant programs. GoMRI-funded outreach coordinators and PIs, the GMT, and outreach partners engaged collectively to share successful methods, build capacity, and partner in joint efforts. Outreach activities were designed to achieve both the GoMRI mission and its legacy goals (https://gulfresearchinitiative.org/aboutgomri/gomri-legacy/; Benoit et al., 2016).

\section{Investigator-Led Outreach}

Consortia were required to plan and budget for outreach and education to complement their research. Individual investigators were not required to implement outreach and education, but were encouraged to do so, and many did. GoMRI did not prescribe outreach programs or activities, allowing each project the flexibility to explore outreach activities suited to their research. Project outreach efforts were extremely effective in promoting GoMRI research results, with individual projects creating programs that directly impacted students, educators, and the public in their local communities.

To maximize the GoMRI investment and ensure GoMRI research and results reached stakeholders, several best 
practices were developed for outreach programs (Beresford et al., 2018). These programs were successful due to early engagement with outreach professionals initiated during proposal development that resulted in realistic and effective plans, specific budgets, and evaluation metrics. GoMRI outreach professionals established regular communication with research widely; this helped to keep members of the GoMRI community engaged in each other's research. The GoMRI website, https://gulfresearchinitiative.org/, which served as the main point of information dissemination for the program, included funding solicitations and research findings, and was linked to the GRIIDC and RIS websites. In addition best practices, and identified partnership opportunities with other GoMRI programs. The RB and GMT shared updates on GMT-led outreach activities, providing a key dissemination channel for these activities to the GoMRI community. A series of webinars, 24 in total, informed the GoMRI research community of ongoing activities. These internal webi-

\section{The GoMRI model provides important guidance for future efforts seeking to}

\section{foster interdisciplinary research...to collectively and comprehensively address global}

threats to ocean ecosystems-certainly an imperative for the immediate future.

research teams in order to understand ongoing research and entrain members of research teams in outreach activities. Each outreach effort capitalized on unique research topics and expertise, infusing new and exciting GoMRI research findings into existing networks and collaborations and broadening impact for relatively low cost (Beresford et al., 2018).

Many of these products are archived on the GoMRI education website (https:// education.gulfresearchinitiative.org/), providing a searchable resource for both formal and informal educators. A special issue of Current: The Journal of Marine Education (2019), authored by collaborative teams of GoMRI outreach coordinators, illustrates how GoMRI researchers approached the process of science and outreach and how GoMRI research proved useful for exploring the Next Generation Science Standards (https://www.nextgenscience.org/).

\section{Program-Led Outreach}

GMT outreach activities were guided by an annual work plan approved by the RB and focused on dissemination of GoMRI to hosting key information, the website includes more than 650 original articles as easy-to-read accounts of ongoing field work and summaries of selected peerreviewed studies, all created in collaboration with researchers. Social media channels auto populated with content posted on the GoMRI website. Quarterly newsletters were produced from 2013 to 2020 in collaboration with GoMRI researchers, outreach coordinators, program managers, and external outreach partners. These newsletters highlighted members of the GoMRI research community and recent research findings. A biweekly e-newsletter provided aggregations of new web content highlighting the GoMRI community, as well as recent publications, data sets, and program announcements.

Several outreach activities were designed specifically to engage the GoMRI research community. Conference calls with PIs, outreach coordinators, RB members, and GMT staff provided opportunities to share and coordinate outreach. Project PIs and outreach coordinators highlighted activities, shared nars provided a unique forum for sharing research not yet published and provided another opportunity to engage the GoMRI research community.

The first annual meeting of the GoMRI research community was held in 2013, as stipulated by the Master Research Agreement, and, with the dedicated help of many partners, it became the annual Gulf of Mexico Oil Spill \& Ecosystem Science (GoMOSES) conference. With an annual attendance of 800 to 1,000 members of the research and resource management community, GoMOSES evolved into a preeminent event for Gulf of Mexico science and oil spill researchers. The venue for the three-to-four-day GoMOSES conference rotated among the Gulf states and featured more than 25 sessions on a variety of topics. Side meetings and informal gatherings at GoMOSES enhanced collaboration and cooperation among the community.

\section{Partner-Led Outreach}

The RB was determined that the program reach the broader public audience. To achieve this objective, GoMRI estab- 
lished partnerships with Smithsonian Ocean Portal, Screenscope Inc., and the four Gulf of Mexico Sea Grant Programs. Each of these partnerships served to bring compelling stories of GoMRI research to the public.

\section{Smithsonian Ocean Portal}

The Smithsonian Ocean Portal was launched in 2010 as an online complement to the Sant Ocean Hall at the Smithsonian National Museum of Natural History. Shortly after the DWH oil spill, the Ocean Portal began to post stories on a Gulf Oil Spill page. In 2013, GoMRI partnered with Ocean Portal to continue sharing oil spill research and results of the work of GoMRI-funded scientists with the public. The Gulf Oil Spill page (http:// ocean.si.edu/gulf-oil-spill) is currently the Ocean Portal's most visited page, with more than 200,000 page views per year.

Ocean Portal writers worked directly with GoMRI researchers to help tell their stories in visually compelling and accessible ways, creating digital communications tools to reach and engage with the public, such as photo slideshows, interactive graphics, and videos. This partnership allowed GoMRI to reach a very large public audience, using unique and high-profile events and an established digital resource with an existing national audience.

\section{Screenscope Inc.}

In 2014, as GoMRI expanded and refined its outreach strategies, the RB created a vision for a documentary to explain how research is done and to tell the GoMRI research story. The goal was to enhance public understanding of science, encourage long-term support for protecting resources in the Gulf of Mexico, and promote science literacy. Through a solicitation process, GoMRI partnered with the documentary film production company Screenscope Inc. to produce three films, Dispatches from the Gulf 1, 2, and 3. Screenings of the films took place at film festivals, museums, and universities, and Dispatches 1 and 2 were broadcast on multiple PBS stations around the United States. Screenscope made these films available to educators free of charge, offering classroom guides and lesson plans. What started as a film project evolved into a multimedia initiative, including short videos and podcasts, to highlight the DWH oil spill research community. The three Dispatches films and the suite of complementary materials comprise a major legacy of the GoMRI program (https://dispatchesfromthegulf.com).

\section{Sea Grant}

In 2014, GoMRI partnered with Sea Grant programs from Florida, Louisiana, Mississippi-Alabama, and Texas to form the Gulf of Mexico Sea Grant Oil Spill Science Outreach Program. A natural connection existed among the organizations, as Sea Grant programs were already based in communities that GoMRI wanted to reach, and GoMRI research was answering questions Sea Grant was being asked. This program shared oil spill science and findings with those who relied on a healthy Gulf of Mexico and used peer-reviewed research findings to answer community questions. Sea Grant programs rely on building relationships and receiving feedback from audiences they serve (https://seagrant.noaa.gov/). Prior to creating the Sea Grant oil spill outreach team, a social network analysis was conducted to identify individuals who were sharing oil spill science information. Once established, the team met with 530 individuals throughout the region, including those identified as key nodes in the social network analysis, to identify questions and needs. The participants framed 449 oil spill science-related questions, which were prioritized based on frequency of mention. The team used this initial information to develop extension products and services explaining the science surrounding topics of greatest interest. The team presented science firsthand at events and convened science seminars for non-scientific audiences, allowing researchers to explain topics in layman terms. To maintain scientific and social relevance, the team engaged with stakeholders and searched the scientific literature to identify discoveries of interest and kept the RB and the GMT apprised of coastal community concerns.

Based on audience requests, Sea Grant team members expanded their scope of work by creating publications in English, Vietnamese, and Spanish; short videos; and a Science-on-a-Sphere module (https://sos.noaa.gov/What_is_SOS/, in partnership with GRIIDC); and by organizing targeted regional workshops and events that expanded their audience beyond the GOM to the national level. The Sea Grant oil spill team members gave more than 200 presentations and convened 48 seminars featuring GoMRI-affiliated presenters, reaching more than 12,000 individuals. The partnership resulted in more than 60 outreach publications and reports that were disseminated throughout the United State and abroad. All outreach publications, seminar information, additional extension products, and survey results are available on the Gulf of Mexico Sea Grant Oil Spill Science Outreach Programs website (https://gulfseagrant. org/oilspilloutreach).

\section{THE GOMRI SCIENTIFIC LEGACY}

\section{Synthesis}

In July 2015, five years after the wellhead was capped, GoMRI reached its halfway point. Four RFPs had been funded, and the fifth was undergoing peer review for selection and announcement that year. Nearly 1,000 data sets had been processed and archived by GRIIDC, and over 500 peer-reviewed publications had been published and catalogued in the RIS (Figure 2). Planning for the fourth GoMOSES conference was underway, and outreach partnerships were expanding. It was then that the $\mathrm{RB}$ focused on development of the sixth and final RFP and on the GoMRI legacy.

The shift in focus to synthesis was reflected in RFP-VI, the final large funding opportunity of the 10-year initiative. Unlike previous calls for propos- 
als, RFP-VI encouraged proposers to emphasize data integration, engage in synthesis between research themes and among consortia, and highlight scientific and technological products of the GoMRI scientific legacy. But these community efforts represented only a part of the synthesis goal.

A group of RB members met in April 2017 to consider gaps in GoMRI synthesis that might not have been addressed by RFP-VI. Before defining the scope of the synthesis, guiding principles were established to ensure the synthesis efforts would be driven by the best available science and that any conclusions reached would be based on peer-reviewed publications. The synthesis team was instructed to take a broader view beyond the Gulf of Mexico and explore the potential for transferability of GoMRI findings to other geographic locations in the United States and around the world. Finally, it was essential to involve the user community, including oil spill responders, nongovernmental organizations, industry, and federal entities, as well as academics, to address effective application of new knowledge gained during GoMRI.

Using the five GoMRI research themes as a framework, the group identified critical gaps, raised key questions, and grouped subject areas into eight core areas (Box 1). Leaders from the GoMRI community were identified for each core area, including RB members assigned to serve as motivators and provide guidance.

For seven of the eight core areas, one or more scientific workshops were

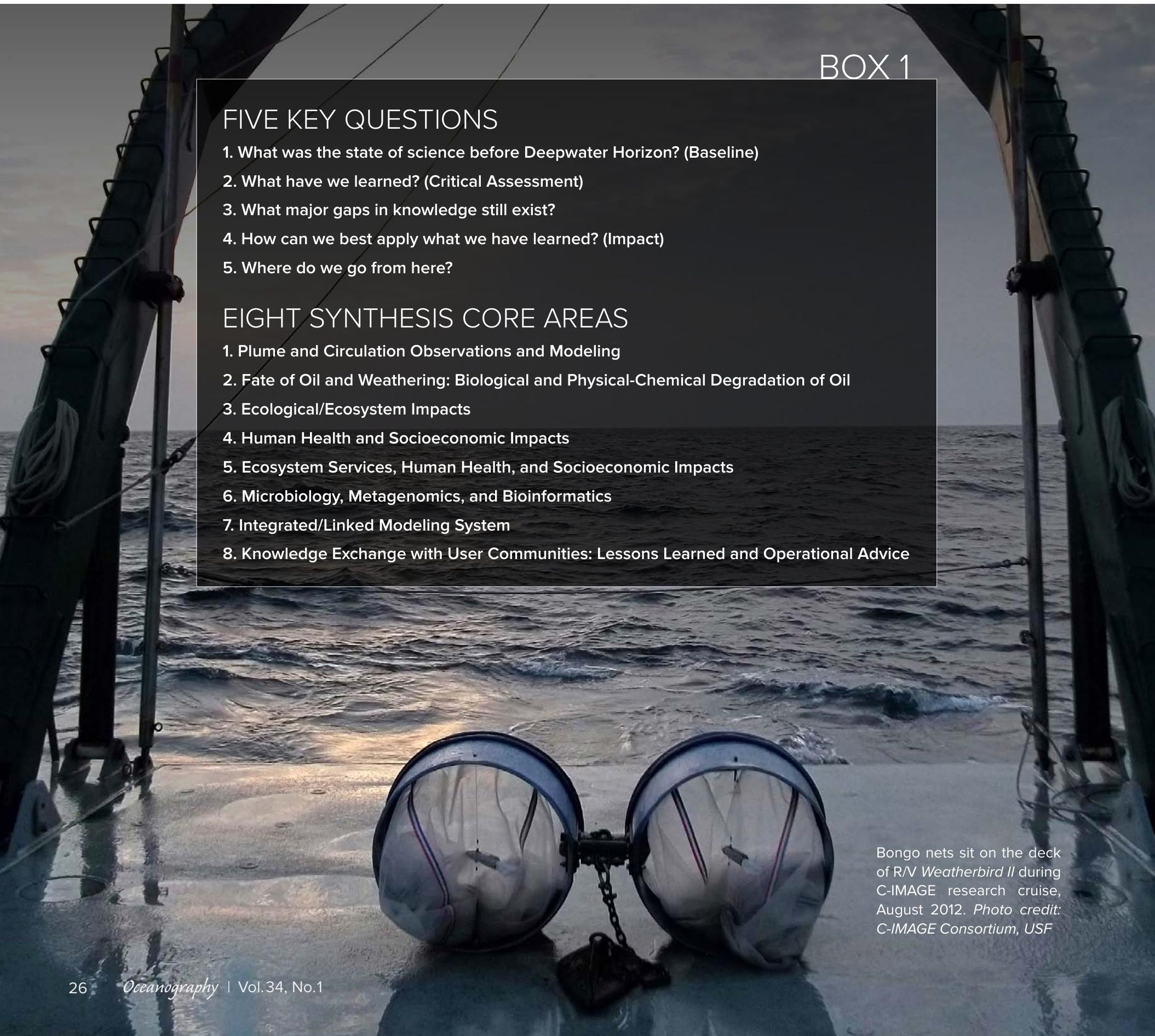


convened. They represent a critical aspect of GoMRI synthesis, each designed as working sessions with specific open access outputs. The products have taken the form of journal articles, special journal issues, books, review papers, recorded webinars, conference presentations, workshop reports, and model frameworks (https://gulfresearchinitiative.org/ gomri-synthesis/products/). RB motivators facilitated coordination between synthesis efforts to avoid duplication and ensure comprehensive coverage. Initially envisioned as a series of five or six workshops, the synthesis effort evolved into a larger and more ambitious undertaking. In total, synthesis leaders completed 20 workshops over two and a half years, representing the collective efforts of approximately 600 experts. The ensemble of synthesis products from this effort forms a major element of the GoMRI legacy.

\section{The GoMRI Model}

Several features of the GoMRI program contributed to the success of this multi-sector partnership. The GoMRI RB played a critical role in ensuring scientific independence of this industry-funded research program. Composition of the board, especially its leadership, was crucial in establishing credibility and building trust within the scientific community. The consistency and collective memory of the RB became an asset as the program progressed. The $\mathrm{RB}$, with the full support of BP, insisted on open data and peer review for both funding solicitations and publications. Notably, the RB had complete discretion in selecting the research to be funded. GoMRI required rigorous project reporting of both financial and research activities quarterly and annually, which allowed real-time tracking of progress. The GoMRI model demonstrates that funding by, and partnership with, industry can support research that is immensely successful, independent, highly reputable, and focused on the best science that addresses a national need.

Because the RB operated indepen- dently and determined scientific direction for the program, flexibility proved to be another key strength of this model. It allowed timely shifts and changes in strategy as needed to exploit opportunities and achieve key objectives. An example is the creation of individual investigator projects addressing a singular research theme. While it was initially anticipated by BP that the research would be done by consortia addressing multiple research themes, the $\mathrm{RB}$ recognized that additional thematic expertise would be gained through individual investigator awards. The RB was also able to move quickly to create funding to fill gaps, for example, supplementary funds for critical sample collection during the 2011 field season (RFP-III), and to complete sample analysis during the final two years of the program.

GoMRI funding brought together diverse interdisciplinary groups and focused their efforts to a common goal, fostering cross-discipline collaborations that yielded advances and impacts otherwise unattainable. The GoMRI model provides important guidance for future efforts seeking to foster interdisciplinary research by bringing together ocean scientists from physical, chemical, biological, and geological backgrounds and chemists, microbiologists, ecologists, fisheries scientists, engineers, numerical modelers, and other experts to collectively and comprehensively address global threats to ocean ecosystems-certainly an imperative for the immediate future. The GoMRI model also offers a path to more powerful and impactful science by utilizing diverse funding and innovative and transformative strategies to advance basic and applied research to meet common national and international needs.

\section{Building Community}

The GoMRI Master Research Agreement was purposely designed to enhance the research capacity of the Gulf of Mexico region. The program drew on an existing network of academic research institutions to create a collaborative community of researchers across all sectors, including government, nongovernmental organizations, and industry. Communication was strengthened among these various groups, illustrated by industry representatives who served in advisory roles to provide guidance on research objectives. Academic researchers participated in government-led oil spill response planning exercises, gaining understanding of the complexities of an operational oil spill response and how to engage in future responses most effectively. Members of critical stakeholder groups from all sectors served as advisors to the synthesis effort, identifying lessons learned, promoting application of research results, and providing operational advice. The enhanced capacity across the Gulf states and expanded collaborations, networking, and integration of the US and global scientific community are GoMRI legacies.

GoMRI research consortia varied in size, number of partnering institutions, and complexity of scope, but all required strategic and adaptive management to coordinate the many components. Rather than having the PI solely responsible, GoMRI encouraged delegation of specific roles, for example, appointment of a program or data manager and an outreach coordinator, and provided funding explicitly for these positions and their tasks. These individuals assisted in coordination and in building a collaborative spirit within consortia. Another important aspect of GoMRI community building was cross-consortia collaboration facilitated by regular internal communication among researchers. The annual GoMOSES conferences built upon those regular interactions and forged long lasting partnerships. Beyond sharing the latest research, the conferences provided opportunities for attendees to interact, resulting in collaborations across sectors, disciplines, research teams, and consortia.

GoMRI had the great benefit of sustained funding for 10 years, and this was particularly empowering. It represented a firm commitment to a network of GoMRI scientists and created a unique 
mentoring opportunity for a new generation of both oil spill and Gulf of Mexico researchers. Resources were made available to prioritize education and training of approximately 1,200 graduate students, 1,000 undergraduates, and nearly 400 early career professionals. Many of the students were recognized for their excellent contributions through the establishment of a GoMRI Scholars Program. A total of 326 graduate students were rec- and leverage in designing their research expeditions. In 2014, GoMRI initiated the Hydrocarbon Intercalibration Experiment (https://gulfresearchinitiative.org/ hydrocarbon-intercalibration-experiment) to advance laboratory quality-assurance/ quality-control practices and to create an opportunity for interlaboratory comparison of and calibration for hydrocarbon compounds. Recognizing traditional challenges encountered in funding ate, but a funds allocation model, assigning a range of funding to each theme prior to award selection, as was considered in early discussions of the $\mathrm{RB}$, might have resulted in a more equitable distribution among the themes.

At the conclusion of any project, documenting what was learned and communicating that knowledge to interested parties is a significant challenge. For GoMRI, the massive scale of the research pro-

\section{The GoMRI model also offers a path to more powerful and impactful science by}

utilizing diverse funding and innovative and transformative strategies to advance basic and applied research to meet common national and international needs.

ognized as scholars, and these students received their scientific training while conducting GoMRI-funded research. Students and early career researchers, in turn, benefited from the interdisciplinary and collaborative research conducted by the consortia and GoMRI, as an entity. They have progressed into professional careers and represent an important legacy of the program.

Private, sustained funding for basic research, combined with the independence and flexibility of the $\mathrm{RB}$, resulted in major research findings. Many procedures, discoveries, and methods made possible by GoMRI funding have wide applicability, beyond the Gulf of Mexico, to future oil spills, regardless of geography. This type of funding-investment by private industry made credible by the RB-also allowed for GoMRI to prioritize activities frequently overlooked by other funding entities. On the advice of the RB committee focused on ship time, the RB allocated ship-time funding within a project rather than following the NSF model of separate funding for ship time. This allowed PIs greater flexibility data repositories, the program provided advanced funding to support GRIIDC's work through 2030, ensuring a GoMRI data legacy. These are some examples of investments that truly supported the research community, providing tools and support needed to produce first rate, peer-reviewed science.

\section{Next Time, Build it Better}

As with any large research effort, there are lessons learned that would benefit the GoMRI program should it be starting today. Integrating research communities that transcend traditional academic departmental structures proved challenging, even with the emphasis that GoMRI had placed on interdisciplinary and collaborative research. For example, GoMRI made a very serious effort to fund research on human health. Engagement of public health experts very early in the development of research themes would have yielded stronger integration of environmental and human health research (Eklund et al., 2019). The decision to fund the best science, regardless of research theme(s), was appropri- gram made scientific synthesis at the end of the program an immense task. Synthesis was incorporated into the final research RFP but, given how critical this effort proved to be in providing scientific value for the public, it probably should have been built into RFPs from the start. Opportunities for cross-project collaboration, as specified in RFP-VI, would have been beneficial to the scientific synthesis if launched earlier in the program. Finally, more and earlier interaction and information exchange, especially in synthesis, would have greatly benefited knowledge transfer to ongoing research programs, the operational community, and oil spill responders post GoMRI. @

\section{REFERENCES}

Benoit, D.S., L.A. Zimmermann, K.H. Fillingham, S.H. Sempier, N.M. Dannreuther, J.B. Ritchie, and K.M. Halanych. 2016. An opportunity to inform and educate through the Gulf of Mexico Research Initiative: Outreach efforts surrounding the Deepwater Horizon oil spill. Oceanography 29(3):38-45, https://doi.org/ 10.5670/oceanog.2016.60.

Beresford, S., K. Fillingham, and T. Miller-Way. 2018. Recommendations for science outreach program development: Perspectives from Gulf of Mexico Research Initiative Consortia. Limnology and Oceanography 27(3):67-75, https://doi.org/10.1002/ lob.10249. 
Campbell, H.A., M.A. Micheli-Campbell, and V. Udyawer. 2018. Early career researchers embrace data sharing. Trends in Ecology and Evolution 34(2):95-98, https://doi.org/10.1016/ j.tree.2018.11.010.

Coastal Response Research Center. 2011. Coordinating R\&D on Oil Spill Response in the Wake of Deepwater Horizon. Workshop Report. Workshop held in Baton Rouge, LA, March 22-24 2011, 19 pp. plus appendices, https://crrc.unh.edu/ sites/crrc.unh.edu/files/media/docs/Publications/ rdworkshop-report_final2011.pdf.

Consortium for Ocean Leadership. Deepwater Horizon Oil Spill: Scientific Symposium Meeting Summary. Symposium held at Louisiana State University, June 3, 2010, 17 pp., http://oceanleadership.org/wp-content/uploads/ 2010/06/DeepwaterHorizonOilSpillSymposiumSummary.pdf.

DHNRDAT (Deepwater Horizon Natural Resource Damage Assessment Trustees). 2016. Deepwater Horizon Oil Spill: Final Programmatic Damage Assessment and Restoration Plan and Final Programmatic Environmental Impact Statement, http://www.gulfspillrestoration.noaa.gov/ restoration-planning/gulf-plan.

Eklund, R.L., L.C. Knapp, P.A. Sandifer, R.C. Colwell. 2019. Oil spills and human health: Contributions of the Gulf of Mexico Research Initiative. GeoHealth 3(12):391-406, https://doi.org/ 10.1029/2019GH000217.

Farrington, J.W., E.B. Overton, and U. Passow. 2021. Biogeochemical processes affecting the fate of discharged Deepwater Horizon gas and oil: New insights and remaining gaps in our understanding. Oceanography 34(1):76-97, https://doi.org/10.5670/ oceanog.2021.118.

Gibeaut, J. 2016. Enabling data sharing through the Gulf of Mexico Research Initiative Information and Data Cooperative (GRIIDC) Oceanography 29(3):33-37, https://doi.org/ 10.5670/oceanog.2016.59.

Institute of Medicine. 2010. Assessing the Effects of the Gulf of Mexico Oil Spill on Human Health: A Summary of the June 2010 Workshop. The National Academies Press, Washington, DC, 200 pp., https://doi.org/10.17226/12949.

McKinney, L.D., J.G. Shepherd, C.A. Wilson, W.T. Hogarth, J. Chanton, S.A. Murawski, P.A. Sandifer, T. Sutton, D. Yoskowitz, K. Wowk, and others. 2021. The Gulf of Mexico: An overview. Oceanography 34(1):30-43, https://doi.org/10.5670/oceanog.2021.115.

McNutt, M., K. Lehnert, B. Hanson, B.A. Nosek, A.M. Ellison, and J.L. King. 2016 Liberating field science samples and data. Science 351(6277):1,024-1,026, https://doi.org/ 10.1126/science.aad7048.

NCBPDHOSOD (National Commission on the BP Deepwater Horizon Oil Spill and Offshore Drilling). 2011. Deep Water: The Gulf Oil Disaster and the Future of Offshore Drilling, Recommendations. 63 pp., https://www.govinfo.gov/content/pkg/GPOOILCOMMISSION/pdf/GPO-OILCOMMISSION-1.pdf.

Pine, J.C. 2006. Hurricane Katrina and oil spills: Impact on coastal and ocean environments. Oceanography 19(2):37-39, https://doi.org/10.5670/ oceanog.2006.61.

Reichman, O.J., M.B. Jones, and M.P. Schildhauer. 2011. Challenges and opportunities of open data in ecology. Science 331(6018):703-705, https://doi.org/10.1126/science.1197962.

Sumaya, C.V., B. Singer, R.R. Colwell, and the GoMRI Research Board. 2013. GoMRI Public Health Workshop Summary. June 2013, 1 p., https://gulfresearchinitiative.org/wp-content/ uploads/GoMRI_PublicHealth_OnePager_Final.pdf.
Tenopir, C., S. Allard, K. Douglass, A.U. Aydinoglu, L. Wu, E. Read, M. Manoff, and M. Frame. 2011. Data sharing by scientists: Practices and perceptions. PLOS ONE 6(6):e21101, https://doi.org/10.1371/ journal.pone.0021101.

Transportation Research Board and National Research Council. 2003. Oil in the Sea III: Inputs, Fates, and Effects. The National Academies Press, Washington, DC, 277 pp., https://doi.org/ 10.17226/10388.

Weiman, S., S.B. Joye, J.E. Kostka, K.M. Halanych, and R.R. Colwell. 2021. GoMRI insights into microbial genomics and hydrocarbon bioremediation response in marine ecosystems. Oceanography 34(1):124-135, https://doi.org/ 10.5670/oceanog.2021.121.

Wiesenburg, D.A., B. Shipp, F.J. Fodrie, S. Powers, J. Lartigue, K.M. Darnell, M.M. Baustian, C. Ngo, J.F. Valentine, and K. Wowk. 2021. Prospects for Gulf of Mexico environmental recovery and restoration. Oceanography 34(1):164-173, https://doi.org/10.5670/oceanog.2021.124.

\section{ACKNOWLEDGMENTS}

GoMRI was a 10-year team effort, and the authors would like to acknowledge the team that provided input to this article, including the entire GoMRI Management Team, for supporting and encouraging the development of this manuscript. Strong leadership from the onset of GoMRI allowed it to thrive. The co-authors and other GoMRI colleagues wish to acknowledge the decade long leadership of RB Chair Rita Colwell, RB Vice Chair Margaret Leinen, Chief Scientific Officer Charles Wilson, Executive Director Michael Carron, and the GoMRI Research Board members: Debra Benoit, Peter Brewer, Richard Dodge, John Farrington, Kenneth Halanych, David Halpern, William Hogarth, Cecilie Mauritzen, Raymond Orbach, Jürgen Rullkötter, David Shaw, Richard Shaw, John Shepherd, Bob Shipp, Burton Singer, Ciro Sumaya, Denis Wiesenburg, and Dana Yoerger.

\section{AUTHORS}

Leigh A. Zimmermann (Izimmermann@ oceanleadership.org) is Senior Program Manager, and Michael G. Feldman (mfeldman@ oceanleadership.org) is Program Manager, both at the Gulf of Mexico Research Initiative (GoMRI), Consortium for Ocean Leadership, Washington, DC, USA. Debra S. Benoit is Director of Research and Sponsored Programs, Nicholls State University, Thibodaux, LA, USA. Michael J. Carron is Program Director, GoMRI, Gulf of Mexico Alliance, Ocean Springs, MS, USA. Nilde Maggie Dannreuther is Coordinator, Northern Gulf Institute, Mississippi State University, Stennis Space Center, MS, USA Katie H. Fillingham is Program Specialist, GoMRI, Consortium for Ocean Leadership, Washington, DC, USA. James C. Gibeaut is Endowed Chair for Coastal and Marine Geospatial Sciences, Harte Research Institute, Texas A\&M University-Corpus Christi, Corpus Christi, TX, USA. Jennifer L. Petitt is Program Manager, American Institute of Biological Sciences, Herndon, VA, USA. Jarryl B. Ritchie is Gulf Coast Liaison, GoMRI, Northern Gulf Institute, Mississippi State University, Stennis Space Center, MS, USA. Rosalie R. Rossi is Project Manager, Harte Research Institute, Texas A\&M University-Corpus Christi, Corpus Christi, TX, USA. Stephen H. Sempier is Deputy Director, Mississippi-Alabama Sea Grant Consortium, Ocean Springs, MS, USA. J. Kevin Shaw is Program Manager, GoMRI, Gulf of Mexico Alliance, Ocean Springs, MS, USA. Jessie L. Swanseen, is Senior Specialist, Project Administration, Consortium for Ocean Leadership, Washington, DC,
USA. Charles A. Wilson is Chief Scientific Officer, GoMRI, Fairhope, AL, USA. Callan J. Yanoff is Program Associate, GoMRI, Consortium for Ocean Leadership, Washington, DC, USA. Rita R. Colwell is Distinguished University Professor, University of Maryland, College Park, MD, USA.

\section{AUTHOR CONTRIBUTIONS}

Leigh A. Zimmermann and Michael G. Feldman are co-lead authors.

\section{ARTICLE CITATION}

Zimmermann, L.A., M.G. Feldman, D.S. Benoit, M.J. Carron, N.M. Dannreuther, K.H. Fillingham, J.C. Gibeaut, J.L. Petitt, J.B. Ritchie, R.R. Rossi, S.H. Sempier, J.K. Shaw, J.L. Swanseen, C.A. Wilson, C.J. Yanoff, and R.R. Colwell. 2021. From disaster to understanding: Formation and accomplishments of the Gulf of Mexico Research Initiative. Oceanography 34(1):16-29, https://doi.org/10.5670/ oceanog.2021.114.

\section{COPYRIGHT \& USAGE}

This is an open access article made available under the terms of the Creative Commons Attribution 4.0 International License (https://creativecommons.org/ licenses/by/4.0/), which permits use, sharing, adaptation, distribution, and reproduction in any medium or format as long as users cite the materials appropriately, provide a link to the Creative Commons license, and indicate the changes that were made to the original content. 